\title{
Valoración territorial del geopatrimonio de la zona costera del sur del Desierto de Atacama, Chile $\left(27^{\circ} \mathrm{S}\right)$
}

\author{
Consuelo Castro ${ }^{1}$,consuelo@uc.cl, Carlos Pattillo ${ }^{2}$, Joaquín Rivera ${ }^{3}$, Álvaro Zuñiga ${ }^{1}$ \\ RESUMEN
}

\begin{abstract}
La zona costera del sur del desierto de Atacama, en el área de Caldera y Copiapó, se caracteriza por sus elementos geomorfológicos y paleontológicos que son reconocidos por su importancia geopatrimonial, a escala nacional e internacional. En este contexto, se efectuó una zonificación de dicho territorio, con el objetivo de generar una base científica que considere dichos elementos naturales de valor, para orientar la gestión y la ordenación integrada de la zona costera del desierto de Atacama en un contexto de protección del geopatrimonio y conservación de la geodiversidad. El litoral se caracteriza por sus terrazas marinas fosilíferas, sus dunas costeras y particularmente, por el gran Mar de Dunas situado en las serranías de la Cordillera de la Costa de Copiapó; además, por la existencia del Área Marino Costera Protegida Isla Grande de Atacama y áreas prioritarias.

Se exponen los resultados de la zonificación del área costera en unidades territoriales valoradas según metodología de análisis espacial multicriterio, integrando las variables de localización de geositios; existencia de áreas de protección; geomorfología de interés, y vegetación. Las unidades territoriales de valoración máxima y muy alta, corresponden a espacios como el Mar de Dunas de Atacama, sitios paleontológicos, acantilados fosilíferos, y el humedal del río Copiapó. En particular, el Mar de Dunas, conforma un conjunto escénico, paisajístico notable, de relevancia regional y nacional; este componente del geopatrimonio del desierto costero del Norte de Chile, junto a otros identificados con máxima valoración, deben ser considerados en las propuestas de ordenación integrada de dicha zona costera, para lo cual aquí se presentan recomendaciones.
\end{abstract}

Palabras clave: zonificación, zona costera, valoración multicriterio, geopatrimonio, Mar de Dunas.

\section{Geoheritage territorial valuation of the coastal zone in southern Atacama Desert, Chile $\left(27^{\circ} \mathrm{S}\right)$}

\begin{abstract}
The southern coastal zone of the Atacama Desert, mainly in the Caldera and Copiapó area, is known for its geomorphological and paleontological features that are recognized nationally and internationally by their geoheritage significance. In this context, a zoning of the territory was carried on, which main objective was to generate a scientific base that takes into account the intrinsic value of these natural elements and that will allow an integrated land use management of this zone.

The coastal area is characterized by fossiliferous marine terraces, coastal dunes and particularly by the great Dune Sea located in the coastal range of Copiapó, in addition to protected marine and coastal areas, as Isla Grande de Atacama. In this way, territorial units ranked by its geoheritage value, were determined using a multicriteria analysis methodology, that integrates different spatial variables as geomorphology, location of geosites, coastal vegetation and existing protected areas. Higher valued territorial units resulted to be the dune sea, paleontological sites, fossiliferous cliffs and the wetland of the estuary of the Copiapó river. In particular, the dune sea, forms a remarkable scenic landscape of regional and national importance and this geoheritage component of the coastal desert of northern Chile, jointly with the other highly valorized features, should be considered in the proposals for integrated management of the coastal zone.
\end{abstract}

Keywords: zoning, coastal zone, multicriteria analysis, geoheritage, sea dunes.

Recibido el 30 de enero de 2013, aceptado 21 de junio de 2013.

Instituto de Geografía, Pontificia Universidad Católica de Chile, Vicuña Mackenna 4860, Santiago, Chile.

Centro de Percepción Remota y SIG

3 Universidad Austral, Valdivia 


\section{INTRODUCCIÓN}

Con el objetivo de establecer una base científica para la ordenación integrada de la zona costera del sur del desierto de Atacama, se realizó un análisis territorial integrado para identificar unidades espaciales de relevancia natural y geopatrimonial, con el fin de propender a su protección y conservación.

Este tipo de iniciativas surgen a partir de la propuesta de UNESCO (1999) sobre la creación de geoparques para la salvaguarda de la geodiversidad. Así, en España, organismos como la JUNTA DE ANDALUCÍA (2008), incluyen al patrimonio abiótico y la geodiversidad en sus estrategias de desarrollo. En Chile actualmente, SCHILLING et al. (2009), entre otros, impulsan la difusión y propuesta de creación del primer geoparque en Conguillío, en la Región de la Araucanía.

En la zona costera de Atacama, varios investigadores, citados más adelante en este artículo, han realizado estudios científicos relevantes en el ámbito de las ciencias de la tierra, como también sobre la vegetación desértica. Dichos trabajos, en conjunto con los resultados de las investigaciones de los autores de este artículo, constituyen una base científica de información para la valoración territorial del geopatrimonio del área de estudio.

Se aplicó una metodología de zonificación basada en un análisis espacial multicriterio considerando tanto los elementos bióticos y abióticos del medio natural, como también, las principales actividades humanas que ejercen presiones e impactos sobre el uso del suelo, y que, en la zona costera en estudio, generan conflictos de incompatibilidad en áreas naturales de valor geopatrimonial y natural. En efecto, según se muestra en la Tabla 1, en el área de estudio hay sitios de gran singularidad geomorfológica, caracterizada en los trabajos de ARAYA-VERGARA (2001); PASKOFF et al. (2003); CASTRO et al. (2010); CASTRO et al. (2012), como también lugares de relevancia geológica y paleontológica definidos por SUAREZ et al. (2003); GODOY et al. (2003), que fueron caracterizados y propuestos como geositios por CASTRO (2007), CASTRO et al. (2010). El territorio se caracteriza por ser el hábitat de ecosistemas desérticos originales de vegetación de niebla y germinación del desierto florido (SQUEO et al. 2008; CASTRO et al. 2013, en prensa). La Tabla 1 presenta la síntesis de los geositios localizados en la zona costera de Atacama y que se caracterizan por poseer elementos singulares constituyentes del geopatrimonio de dicho territorio.

La geomorfología de la zona costera en Caldera y Copiapó, se caracteriza por un borde litoral de acantilados marinos y salientes rocosos que alternan con bahías con sistemas de dunas activas cuya fuente de alimentación, según PASKOFF et al. (2003), son las playas situadas al norte de la desembocadura del río Copiapó (Fig. 1) 

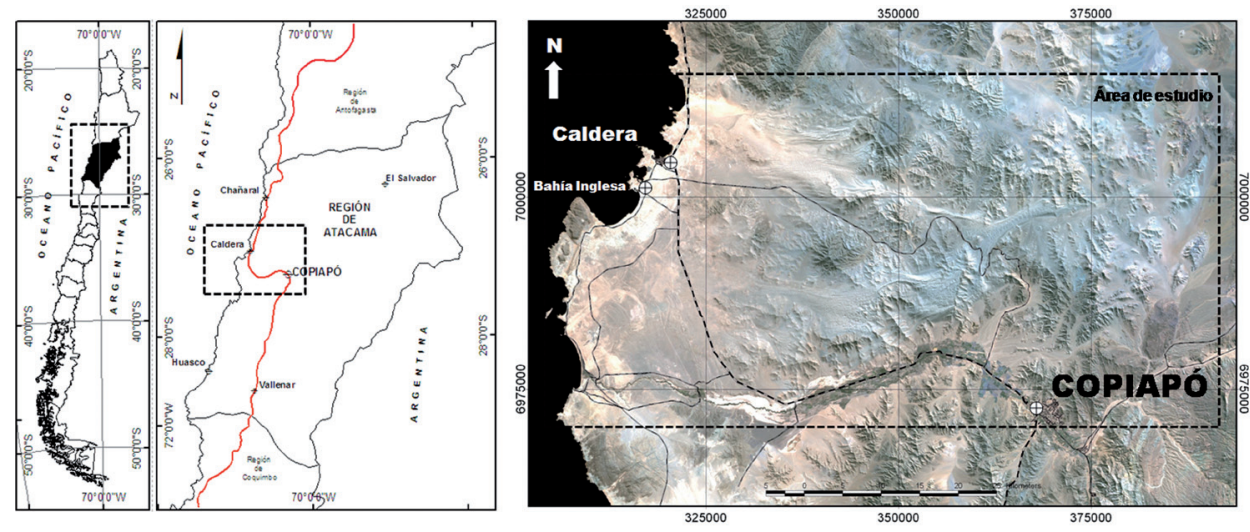

Fig.1. Zona costera sur del desierto de Atacama, Caldera $\left(27^{\circ} \mathrm{S}\right)$.

Fig.1. Coastal Zone in the Southern Atacama Desert, Caldera $\left(27^{\circ} \mathrm{S}\right)$.

Tabla 1: Geositios de interés patrimonial en la zona costera de Atacama.

\begin{tabular}{|c|c|}
\hline Geositio & Descripción \\
\hline $\begin{array}{c}\text { Terrazas y acantilados } \\
\text { marinos de Chorrillos } \\
\left(27^{\circ} 12^{\prime} \mathrm{S} / 70^{\circ} 56^{\prime} \mathrm{O}\right)\end{array}$ & $\begin{array}{l}\text { Labrados en rocas sedimentarias marinas del Mioceno y Plioceno con fauna } \\
\text { fosilifera (GODOY et al. 2003). Se reconocen pliegues y fallas que revelan } \\
\text { actividad neotectónica y también, atractivas formas residuales por erosión } \\
\text { diferencial en las terrazas y en los acantilados marinos activos. Sitio de gran } \\
\text { interés científico y escénico (CASTRO 2007; CASTRO et al. 2010). }\end{array}$ \\
\hline $\begin{array}{c}\text { Duna Ramadas } \\
\left(26^{\circ} 59^{\prime} \mathrm{S} / 70^{\circ} 45^{\prime} \mathrm{O}\right)\end{array}$ & $\begin{array}{l}\text { Duna litoral compuesta por sucesiones de dunas longitudinales activas de } \\
\text { varios kilómetros de largo; sus arenas se componen de un alto contenido } \\
\text { de carbonato de calcio por presencia de bioclastos de origen marino } \\
\text { (PASKOFF et al. 2003; CASTRO 2007; CASTRO et al. 2010). }\end{array}$ \\
\hline $\begin{array}{l}\text { Quebrada La Higuera } \\
\left(27^{\circ} 16^{\prime} \mathrm{S} / 70^{\circ} 55^{\prime} \mathrm{O}\right)\end{array}$ & $\begin{array}{l}\text { Extraordinario conjunto de formas remanentes de erosión por acciones } \\
\text { fluviales y eólicas tales como cerros testigo, yardang, cornisas y escalones } \\
\text { de denudación labrados en la secuencia sedimentaria marina de la formación } \\
\text { Bahía Inglesa (GODOY et al. 2003; CASTRO 2007; CASTRO et al. 2010). }\end{array}$ \\
\hline $\begin{array}{l}\text { Yacimiento fosilífero } \\
\text { Bahía Inglesa } \\
\left(27^{\circ} 09^{\prime} \mathrm{S} / 70^{\circ} 53^{\prime} \mathrm{O}\right)\end{array}$ & $\begin{array}{l}\text { Terrazas marinas erosionadas por profundas quebradas debidos a la erosión } \\
\text { fluvial y pluvial. Los estratos sedimentarios contienen fauna fosilífera de } \\
\text { vertebrados marinos de hasta } 23 \text { millones de años de antigüedad (SUAREZ } \\
\text { et al. 2003; GODOY et al. 2003). }\end{array}$ \\
\hline $\begin{array}{l}\text { Humedal costero Río } \\
\text { Copiapó } \\
\left(27^{\circ} 18^{\prime} \mathrm{S} / 70^{\circ} 55^{\prime} \mathrm{O}\right)\end{array}$ & $\begin{array}{c}\text { Situado al norte de la desembocadura del río Copiapó, tras un cordón } \\
\text { litoral arenoso de } 4 \text { kilómetros de longitud. Variedad de especies vegetales } \\
\text { hidrófilas como también, sitio de nidificación de avifauna y albergue de aves } \\
\text { migratorias (CASTRO 2007; CASTRO et al. 2010). }\end{array}$ \\
\hline $\begin{array}{c}\text { Mar de Dunas de } \\
\text { Atacama }\end{array}$ & $\begin{array}{l}\text { Conjunto de seis campos de dunas continentales desérticas que conforman } \\
\text { un erg con una superficie de } 335 \mathrm{~km} 2 \text {. Se localizan en valles al interior } \\
\text { de la Cordillera de la Costa de Copiapó. Se presentan como sucesiones } \\
\text { de dunas estabilizadas, semiactivas y activas con formas compuestas } \\
\text { barjanoides, lineales y transversales (ARAYA-VERGARA 2001; PASKOFF } \\
\text { et al. 2003; CASTRO et al. 2012). } \\
\text { En el sector del Cerro Medanoso, las dunas son activas y alcanzan } 1.643 \text { m } \\
\text { de altitud; se distinguen conjuntos complejos de dunas desérticas del tipo } \\
\text { estrella y piramidales (CASTRO et al. 2012). }\end{array}$ \\
\hline
\end{tabular}

Fuente: Elaboración propia 
El conjunto de formas corresponde a una sucesión de terrazas marinas escalonadas muy bien conservadas, labradas en areniscas marinas fosilíferas del mioceno-plioceno (Godoy et al. 2003); dichas terrazas se extienden 20 kilómetros al interior del continente y hasta 300 m.s.n.m, hasta contactarse con la base de la Cordillera de la Costa, en las proximidades de Copiapó $\left(27^{\circ} \mathrm{S}\right)$. Los cerros de la Cordillera de la Costa confinan el extenso conjunto dunario del Mar de Dunas de Atacama, conformado por voluminosas dunas semiactivas y activas que cubren una superficie de $335 \mathrm{~km}^{2}$; el erg tiene una morfología compleja por la influencia de la topografía de valles y cerros subyacentes (Fig. 1). Este sistema de dunas desérticas es un rasgo geomorfológico relevante de la zona costera de Atacama, debido tanto a su extensión y volumen, como a su originalidad científica y paisajística, aspectos que se fundamentan en el artículo de CASTRO et al. (2012), donde también se explicitan los estudios previos de otros autores en el área de estudio. Así, debido a que la masa arenosa de las dunas fue heredada de condiciones paleogeográficas diferentes de las actuales, PASKOFF et al. (2003), las denominan dunas remanentes que representan un tesoro morfogenético o Formenschatz, según la acepción de MORTENSEN (1972), refrendada por ARAYA-VERGARA (2001). Este último autor señala que las sucesiones de formas del Mar de Dunas, representan las distintas etapas evolutivas que dieron origen a su instalación y establece una hipótesis al respecto. Además, en las cartas geológicas de Caldera y Copiapó, a escala 1:100.000, realizadas por GODOY et al. (2003) y por ARÉVALO (2005), se representan las áreas cubiertas con arenas de origen eólico existentes en el área de estudio. Dichos autores reconocen tipos de dunas lineales, depósitos mantiformes y campos de dunas parabólicas en sucesiones de crestas, filos y familias de formas del Holoceno y Pleistoceno.
En el área las condiciones de aridez están determinadas por el Anticiclón Subtropical del Pacífico Sur y la corriente fría de Humboldt. La oscilación térmica diaria es moderada con $15.5^{\circ} \mathrm{c}$ de temperatura promedio anual; las escasas lluvias alcanzan $30 \mathrm{~mm}$ de promedio anual en Caldera y Copiapó. Ocasionalmente, ocurren lluvias con montos superiores a $100 \mathrm{~mm}$, asociadas a eventos El Niño - Oscilación Sur (ENSO); estas lluvias provocan la germinación espontánea de semillas en estado de latencia en los mantos arenosos que cubren las terrazas marinas situadas bajo los 500 metros de altitud, fenómeno conocido en Chile como "desierto florido", originalidad que también otorga un gran valor natural al territorio costero de este sector de Atacama (SQUEO et al. 2008).

El clima desértico costero nuboso, permite la presencia de vegetación de niebla, bromeliáceas del género Tillandsia las cuales, de acuerdo a un estudio de los autores sobre los factores geográficos de su localización, (CASTRO et al. 2013, en prensa), alcanzan en este sitio, $27^{\circ} \mathrm{S}$, la posición más austral de su distribución en el desierto costero chileno. En efecto, las dunas y los mantos eólicos tienen distintos estados de estabilización según la presencia de vegetación. Esporádicamente ocurre la floración del desierto en los años lluviosos y su distribución espacial ocurre en paños continuos situados entre los 100 y 700 m.s.n.m., cubriendo los planos inclinados y la superficie de las terrazas marinas más altas que poseen sustratos arenosos estabilizados y semiestabilizados (CASTRO et al. 2013, en prensa) (Fig.2). Dichos datos se utilizaron en este trabajo, para la puesta en valor de la vegetación asociada al medio dunario desértico, junto a los resultados de las investigaciones de (SQUEO et al. 2007) sobre especies vegetales vulnerables en Atacama, según se explica en la metodología. 


\section{MATERIALES Y MÉTODOS}

La metodología de análisis espacial aplicada en este estudio consistió en una evaluación multicriterio utilizando un Sistema de Información Geográfico (BARREDO 1996), integrándose los criterios de valoración que son: áreas actuales de protección, geositios, geomorfología y vegetación: con los elementos territoriales de relevancia geopatrimonial del área de estudio, con el fin de obtener unidades espaciales valoradas, como instrumento para la ordenación del territorio, según se observa en la figura 2 y Tabla 1.

Se efectuó un procedimiento en tres etapas consistentes en: a) asignación de valores individuales de cada elemento que integra un criterio de valoración (Tabla 1), b) determinación de los ponderadores o peso relativo de cada criterio (Tabla 2), c) procesamiento espacial de la cartografía (BARREDO 1996), junto a la ponderación de los polígonos resultantes que conforman áreas para la determinación de una zonificación en unidades espaciales valoradas, según se observa en la secuencia de síntesis de la figura 2 , que son explicados más adelante en el texto.

Para llevar a cabo el análisis multicriterio se utilizó una fuente de datos generada por los autores en estudios previos. Esto se refiere a las coberturas de información espacial sobre unidades geomorfológicas de la zona costera de Atacama (CASTRO et al. 2012); la localización y determinación de geositios en el área, definidos por CASTRO (2007), CASTRO et al. (2010) y finalmente, el estudio sobre la distribución espacial de la vegetación en el área (CASTRO et al. 2013, en prensa). Por su parte, la cobertura sobre áreas de conservación, se basó en la información de SQUEO et al. (2008). La cobertura de unidades geomorfológicas necesaria para la determinación de las unidades espaciales, figuras 2 y 3 , fue generada por una investigación previa (CASTRO et al. 2012), en donde se emplearon imágenes de alta resolución del Landsat 5 y Landsat 7 con sus sensores TM y ETM, además de imágenes Google Earth de los años 2003 al 2011. Para georreferenciar las fotografías aéreas e imágenes Landsat, se generó un Modelo Digital de Elevación y puntos de control obtenidos con GPS. Dichas fotografías e imágenes se utilizaron para efectuar la determinación de los contornos de las unidades geomorfológicas; la dirección de lineamientos y orientación de crestas en el caso de las dunas continentales; además de los aspectos morfoestructurales de las terrazas marinas, vertientes y valles del área de estudio. El análisis e interpretación geomorfológico se complementó con levantamientos de datos en terreno a partir de recorridos del área de estudio con GPS; reconocimiento de las diferentes formaciones superficiales tales como coberturas eólicas, mantos de arenización, costras calcáreas, pavimentos desérticos, entre otros, presentes en el área de estudio; la distribución de la cubierta vegetal; medición de radiometría de campo para el estudio de firmas espectrales e interpretación digital de las imágenes. Realizando los procedimientos anteriores se elaboró la cartografía de unidades geomorfológicas y se delimitaron los márgenes del Mar de Dunas de Atacama, según se observa en la figura 3. En el artículo de CASTRO et al. (2012), también se establecieron los principales usos humanos que se llevan a cabo en el área, los cuales se señalan en la Tabla 4 para las unidades territoriales de interés geopatrimonial.

Las coberturas temáticas de vegetación que alimentaron la base de datos del sistema de información geográfico para el establecimiento de unidades espaciales valoradas, (Fig. 2 y Fig.3), son las coberturas de distribución del desierto florido y de localización de la vegetación de niebla, cuya metodología se expone detalladamente en el 
artículo ya citado de CASTRO et al (2013, en prensa). Para establecer la distribución espacial de los campos de tillandsias, que corresponden a vegetación xérica permanente, se efectuó el reconocimiento visual de los patrones texturales de tillandsias, mediante el análisis de imágenes Digital Globe disponibles en Google Earth. La validación de los patrones texturales de tillandsias vivas y muertas, se realizó en campañas de terreno donde se constató que la especie dominante es Tillandsia landbeckii, CASTRO et al. (2013, en prensa).

Para la detección de la distribución de la vegetación temporal del desierto florido (Fig. 3), se procesaron digitalmente imágenes obtenidas por los satélites Landsat 5-7 y Aster, y se dispuso de una serie de imágenes tomadas en años secos y en años húmedos. Así, basándose en las diferencias de valores de reflectancia entre la banda del rojo, que tiene mínima reflectancia por absorción de esas longitudes de onda por la clorofila, y la banda del infrarrojo cercano, se pueden separar los pixeles que tienen vegetación de los que no tienen. Para ello se utilizó el Índice Vegetacional de Diferencias Normalizadas o NDVI (CASTRO et al. 2013, en prensa); así, el procesamiento de las imágenes satelitales a partir del cálculo del NVDI, junto al levantamiento de terreno y al reconocimiento de patrones texturales de la vegetación, fuerón métodos complementarios que permitieron definir con certeza, tanto los contornos de las áreas vegetadas como los de los campos de dunas localizados en el área.

En cuanto al procedimiento de asignación de valor a los elementos del geopatrimonio, se consideró los principios recomendados por CENDRERO (1996); PEREIRA et al. (2007); CARCAVILLA et al. (2007), según se comenta más adelante y en la discusión. También, los criterios de calificación se determinaron con la consulta y participación en terreno de varios expertos, geólogo (MARQUARDT et al. 2007); paleontólogo (SUAREZ et al. 2003); arquitecto (Francisco
Chirino); ingeniero forestal (Jorge Espinoza), ambos funcionarios de la Oficina de Planificación Territorial del Gobierno Regional de Atacama; la Asociación de Raidistas de Atacama, principales usuarios del Mar de Dunas, estuvo representada por su gerente (Patricio Ríos). De igual manera, se efectuaron talleres de consulta de opinión y salidas a terreno con representantes de los organismos regionales y locales del Servicio Nacional de Turismo; Ministerio de Bienes Nacionales; Museo Paleontológico de Caldera; funcionarios representantes de los Municipios de Caldera y Copiapó, respectivamente. Finalmente, también se contó con la participación, tanto en consultas como en terreno, de los profesores de la Universidad de Cádiz, España, Juan Manuel Barragán y María Luisa Perez-Cayeiro, especialistas en ordenación integrada de áreas costeras.

Así, para la determinación de unidades espaciales valoradas, se procedió de acuerdo a la secuencia de pasos metodológicos señalada en la figura 2; la primera etapa consistió en determinar los criterios de valoración: 1) áreas actuales de protección, 2) geositios, 3) geomorfología y, 4) vegetación. Así mismo, se definieron los elementos específicos que componen a cada uno de estos criterios, según se señala en la Tabla 1, generándose una cartografía para cada tema, como se observa en la figura 3, con las respectivas coberturas ya nombradas.

Cabe señalar aquí que, por tratarse de la valoración del geopatrimonio, las variables relativas a geomorfología, geología, paleontología son determinantes en la asignación de valores. Los autores adaptaron las recomendaciones para el inventario y valoración del geopatrimonio hechas por CENDRERO (1996), sobre los criterios para la valoración del patrimonio abiótico. También, se consideró el trabajo de PEREIRA et al. (2007) quienes otorgan y fundamentan la relevancia del criterio geomorfológico para la valoración del geopatrimonio, como es el caso de este estudio en Atacama. Junto 
a lo anterior, también se consideraron las recomendaciones de SCHILLING et al. (2007) referidas a las pautas que debieran aplicarse en Chile para el inventario y cuantificación del geopatrimonio nacional.

Con el fin de hacer comparables los criterios de valoración, se estableció con el método de subjetividad aceptada recomendado por CARACAVILLA et al. (2007), una escala relativa de 0 a 10 , para su estandarización, donde el cero (0) es para caracterizar a un elemento que no tiene importancia y puede ser reemplazado sin inconvenientes por cualquier uso humano, y el valor 10 para indicar que es un elemento de valor inconmensurable que debe ser protegido o estudiado en detalle antes de permitir un uso diferente al natural. Los valores intermedios se definen como 2,5 valor medio (interesante), 5 valor alto (muy interesante) y 7,5 valor muy alto (excepcional) De acuerdo a lo anterior, para el criterio 1) áreas de protección, se categorizaron sus elementos de 0 a 10; como también para el criterio 2) geositios, con sus respectivos elementos categorizados de igual forma; y así, igualmente para los criterios 3) geomorfología y 4) vegetación. Con este procedimiento se hacen comparables por su nivel de importancia, elementos de distinto tipo, como por ejemplo una planta y la arena; así, un elemento con valor 10 es más importante que uno con valor 5 , cualquiera sea el criterio analizado.

Según lo explicado precedentemente, se asignó la escala de 0 a 10 a cada uno de los elementos que componen los criterios estudiados. Dado que estos valores son relativos y la percepción de importancia puede diferir según las distintas visiones personales, se efectuaron consultas y opiniones al grupo de expertos señalados precedentemente, especialistas conocedores del área de estudio, para que asignaran la escala de 0 a 10 a cada elemento de los criterios de valoración definidos. El resultado obtenido se promedió y agregó a la base de datos del tema respectivo para ser utilizado en la generación del tema de síntesis final, expresado en una cartografía que integra todos los elementos, resultando una carta de zonificación de la zona costera en áreas valoradas, según se muestra en la figura 4 .

En la segunda etapa, se solicitó indicar a cada integrante del grupo de expertos, la importancia relativa de un criterio con respecto a otro, por ejemplo: ¿cuánto más importante es la vegetación que un elemento geomorfológico o que un yacimiento paleontológico? La respuesta se expresa asignando un valor igual a 1 si ambos criterios son de igual importancia; o bien, un valor de 3, 5, o 7 si se considera de una importancia relativa mayor, y hasta el valor 9, que es el mayor grado o jerarquía de importancia relativa. Si el criterio analizado es menos importante, entonces los valores se aplican en un sentido inverso, es decir, $1 / 3,1 / 5,1 / 7$ o $1 / 9$ para indicar una menor importancia en distintos grados o jerarquías. Dado que se evalúan 4 criterios, se debe comprobar la consistencia de los valores asignados, evitando incongruencias en los valores de importancia determinados.

A continuación, los valores obtenidos se ingresaron en una Matriz de SAATY, la que es muy utilizada en análisis multicriterio y cuyo resultado permite obtener un valor de ponderación que se aplicará a cada criterio evaluado (SAATY et al. 2001). Dado que cada especialista del grupo evaluador puede tener una percepción de importancia relativa diferente para cada criterio, se promedian los valores de cada uno de ellos, obtenidos para la Matriz de SAATY, cuidando que la suma de los porcentajes promedio sea de un $100 \%$.

En la etapa tres, utilizando un sistema de información geográfico ArcGIS se efectuó el procesamiento espacial para generar una cobertura de síntesis valorada (Fig. 5), de acuerdo a los ponderadores obtenidos en la etapa anterior. El proceso consiste en la unión espacial de los cuatro temas, expresión espacial de los criterios, cuyo resultado se obtiene de la sumatoria de cada valor ponderado según su correspondiente criterio, 
obteniendo polígonos en cuya base de datos hay un campo de valor final (VF) que contiene el valor de 0 a 10 de cada unidad espacial. Dicho procedimiento se expresa en la siguiente fórmula.

$$
\Sigma v \cdot p=v_{a} \cdot p_{a}+v_{b} \cdot p_{b}+\ldots
$$

De este modo, se genera un nuevo campo que contendrá el resultado de combinar los ponderadores de cada criterio. Por ejemplo, un polígono que resultó de la unión de vegetación con valor 8 , geositio con valor 10 , zona de protección con valor $0 \mathrm{y}$ geomorfología con valor 5 , tendrá un valor de síntesis final de $\mathrm{VF}=8 * 0.152+10 *$ $0.4869+0 * 0.2393+5 * 0.1218=4.2$.

De esta forma, los miles de polígonos resultantes de la unión espacial de los cuatro criterios tendrán a su vez valores que van de 0 a 10. El paso siguiente fue fijar rangos para agrupar las zonas con los siguientes valores y significados: poco significativo (0 a 2,5); valor alto (2,5 a 5); valor muy alto (5 a 7,5); y valor máximo (7,5 a 10).

Las zonas resultantes son analizadas en sus características particulares según los criterios que le otorgan valor, según se observa en la figura 5. A su vez, son contrastados con los usos y actividades que se realizan en la zona y que afectan negativamente, o que podrían hacerlo. A partir de este análisis se elabora una propuesta de recomendaciones para el manejo y uso adecuado de las distintas unidades espaciales que integran elementos de valor geopatrimonial, como se muestra en la Tabla 5.

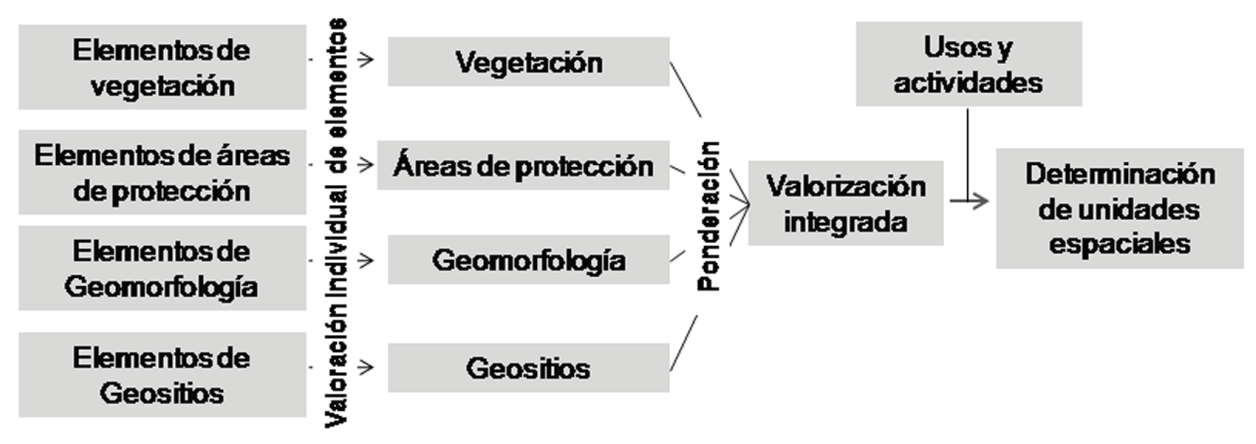

Fig. 2. Esquema metodológico simplificado de valoración integrada.

Fig. 2. Simplified Methodological Scheme for Integrated Valorization.

\section{RESULTADOS}

\section{Procedimiento de evaluación espacial multicriterio de la zona costera y Mar de Dunas}

Según el procedimiento metodológico explicado, se efectuó el proceso conducente a la determinación y valoración de unidades espaciales para la zonificación según se observa en las figuras 3 y 4 . Los resultados del procesamiento de datos de cada una de las etapas realizadas son los siguientes:

Etapa 1: los expertos asignaron valores de 0 a 10 a cada uno de los elementos que componen cada criterio de valoración y el resultado final asignado a la base de datos del tema o criterio es el promedio de dichos valores, tal como se muestra en la Tabla 1. 
La desviación estándar en la Tabla 1, es una indicación de la variabilidad u homogeneidad de los valores asignados por los especialistas. Así, un valor pequeño indica un acuerdo en asignar ese peso y un valor grande de la desviación estándar, indica que en los valores asignados por los especialistas hubo mayor discrepancia; sin embargo, la desviación más alta $(2,2)$ es despreciable y no pone en cuestión el valor promedio resultante.
Etapa 2: A partir de las matrices de SAATY, generadas por los especialistas nombrados en la metodología, participando como grupo de expertos, se obtuvo el factor de ponderación promedio para cada uno de los criterios, como se observa en la Tabla 2. Los resultados indican que los especialistas asignaron un peso mayor al tema o criterio que comprende los geositos y las áreas protegidas, siendo más baja la ponderación de los criterios de geomorfología y vegetación.

TABla 1: VAlORES INDIVIdUALES DE CADA ELEMENTO SEGÚN LOS EXPERTOS.

Table 1: Single Values for each Element according to eXPerts.

\begin{tabular}{|c|c|c|c|}
\hline Criterio o Tema & Elemento & $\begin{array}{l}\text { Valor Asignado } \\
\text { Promedio }\end{array}$ & Desviación Estándar \\
\hline \multirow{4}{*}{ Vegetación } & Desierto Florido & 10 & 0.5 \\
\hline & Humedales & 8 & 1.4 \\
\hline & Tillandsias & 6 & 0.9 \\
\hline & Otra vegetación & 4 & 1.0 \\
\hline \multirow{5}{*}{$\begin{array}{l}\text { Áreas de } \\
\text { protección }\end{array}$} & Sitios Prioritarios CONAMA & 8 & 2.2 \\
\hline & $\begin{array}{l}\text { Área Marino Costera Protegida } \\
\text { (AMCP) }\end{array}$ & 9 & 0.8 \\
\hline & Atractivos Turísticos & 7 & 1.4 \\
\hline & Sitios Paleontológicos & 10 & 0.8 \\
\hline & Sitios Arqueológicos & 9 & 1.7 \\
\hline \multirow{6}{*}{ Geositios } & $\begin{array}{l}\text { Terrazas y Acantilados } \\
\text { marinos de Chorrillos }\end{array}$ & 9 & 1.2 \\
\hline & Duna Ramadas & 7 & 1.7 \\
\hline & Quebrada La Higuera & 9 & 0.4 \\
\hline & $\begin{array}{l}\text { Yacimiento fosilífero Bahía } \\
\text { Inglesa }\end{array}$ & 9 & 1.2 \\
\hline & Humedal Costero Río Copiapó & 9 & 1.5 \\
\hline & Mar de Dunas de Atacama & 9 & 1.0 \\
\hline \multirow{6}{*}{ Geomorfología } & Dunas desérticas & 9 & 0.8 \\
\hline & Terrazas marinas & 6 & 1.7 \\
\hline & $\begin{array}{l}\text { Cerros de la Cordillera de la } \\
\text { Costa }\end{array}$ & 3 & 1.6 \\
\hline & Valles & 5 & 1.8 \\
\hline & $\begin{array}{c}\text { Planos inclinados y glacis } \\
\text { aluvio coluviales }\end{array}$ & 4 & 1.5 \\
\hline & Playas & 7 & 1.6 \\
\hline
\end{tabular}


TAbla 2: Ponderadores de VAloración territorial.

Table 2: Weights for Territorial Valuation.

\begin{tabular}{|c|c|c|}
\hline Criterio & $\begin{array}{c}\text { Ponderador Promedio en } \\
\text { Porcentaje }\end{array}$ & $\begin{array}{c}\text { Ponderador Promedio como } \\
\text { factor de cálculo }\end{array}$ \\
\hline Vegetación & $15 \%$ & 0.152 \\
\hline Áreas Protegidas & $24 \%$ & 0.2393 \\
\hline Geositios & $49 \%$ & 0.4869 \\
\hline Geomorfología & $12 \%$ & 0.1218 \\
\hline Total & $100 \%$ & 1 \\
\hline
\end{tabular}

Etapa 3: Al efectuar la unión espacial de los temas en el sistema de información geográfico Arc/GIS, se genera como resultado una serie de polígonos cuya base de datos contiene un campo para almacenar los valores de cada criterio utilizado. A esta Tabla se agrega un nuevo campo, Valor Final, el cual recoge el resultado de la aplicación de los ponderadores definidos en la etapa 2 , a cada uno de los criterios jerarquizados de $0 \mathrm{a}$ 10 , es decir $\mathrm{VF}=($ Vegetación $*$ Ponderación - Vegetación $)+$ (Zonas Protección Ponderación -Zonas Protección $)+($ Geositio * Ponderación -Geositio) + (Geomorfología * Ponderación -Geomorfología). La Tabla 3 , es un ejemplo de la base de datos que resulta de este proceso.

Tabla 3: Ejemplo de la base de datos con el Resultado de aplicación de ponderadores.

TABle 3: Data baSe EXAMPle WITH RESUlts FOR WEIGHTS APPLICATION.

\begin{tabular}{|c|c|c|c|c|c|c|c|c|c|}
\hline \multirow{2}{*}{ Polígono } & \multicolumn{2}{|c|}{ Vegetación } & \multicolumn{2}{c|}{ Zonas de protección } & \multicolumn{2}{c|}{ Geositios } & \multicolumn{2}{c|}{ Geomorfología } & \multirow{2}{*}{\begin{tabular}{c} 
Valor \\
\cline { 2 - 9 }
\end{tabular}} \\
\cline { 2 - 10 } & $\mathrm{V}$ & $\mathrm{P}$ & $\mathrm{V}$ & $\mathrm{P}$ & $\mathrm{V}$ & $\mathrm{P}$ & $\mathrm{V}$ & $\mathrm{P}$ & Final \\
\hline 1 & 0 & 0.152 & 0 & 0.239 & 0 & 0.487 & 4 & 0.122 & 0.5 \\
\hline 2 & 10 & 0.152 & 7 & 0.239 & 9 & 0.487 & 6 & 0.122 & 8.3 \\
\hline 3 & 10 & 0.152 & 10 & 0.239 & 0 & 0.487 & 9 & 0.122 & 5.0 \\
\hline 4 & 8 & 0.152 & 9 & 0.239 & 9 & 0.487 & 7 & 0.122 & 8.6 \\
\hline 5 & 6 & 0.152 & 7 & 0.239 & 7 & 0.487 & 3 & 0.122 & 6.4 \\
\hline
\end{tabular}

$\mathbf{V}=$ Valor $/ \mathbf{P}=$ Ponderador

En la figura 3 se muestran las coberturas de vegetación, geomorfología, geositios y áreas de protección, con sus correspondientes valores de ponderación relativa, según se muestra en la Tabla 2. Se observa que las áreas de protección y la existencia de geositios en la zona costera, son criterios de alta ponderación, debido a su elevada singularidad, la que fue definida en estudios realizados anteriormente (CASTRO 2007; CASTRO et al. 2010); como también los de ARAYA-VERGARA (2001) y PASKOFF et al. (2003) para el Mar de Dunas de Atacama. Es relevante el valor que otorgan las áreas protegidas en la zona costera; tal es el caso del Área Marino Costera Protegida de Múltiples Usos (AMCP-MU) Isla Grande 
de Atacama (SQUEO et al.2007); como también, las áreas prioritarias de protección de la vegetación endémica del desierto chileno, (SQUEO et al. 2008; CASTRO et al. 2013 en prensa), que son los elementos determinantes de valoración de la zona costera en estudio.

\section{Determinación de unidades territoriales de interés geopatrimonial y natural}

La distribución espacial de las unidades territoriales valoradas de la zona costera de Atacama, permite identificar 12 áreas de alto interés geopatrimonial y natural, según se observa en la Tabla 4 y figura 5 . Dichas unidades reúnen combinaciones de los diferentes elementos de cada criterio utilizado en la valoración del área en estudio.
A partir de la delimitación y caracterización de las 12 unidades de valor geopatrimonial y natural representadas en la figura 5, se procede al análisis de cada unidad para distinguir aquellos criterios y elementos que son determinantes para su valoración respectiva. En dicho análisis se considera el rango de importancia según la valoración integrada obtenida y los elementos relevantes que se localizan dentro de la unidad territorial, según se muestra en la Tabla 4. Además, se identifican los usos y actividades actuales que afectan el medio natural y que deben ser considerados con especial atención en las zonas con alto valor, lo cual resulta fundamental para la recomendación de usos y actividades compatibles en cada unidad.
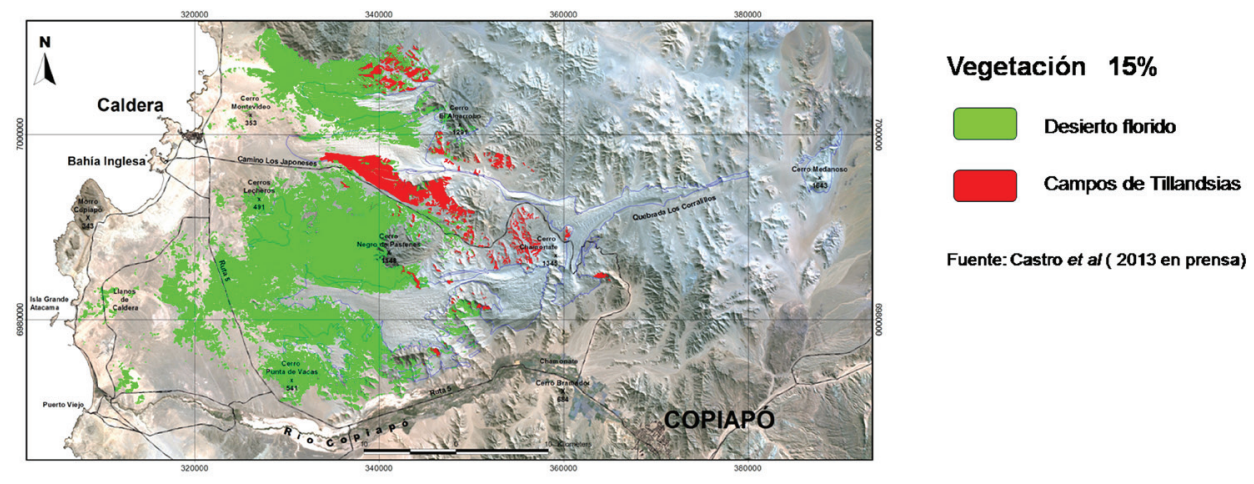

Fuente: Castro et al ( 2013 en prensa)

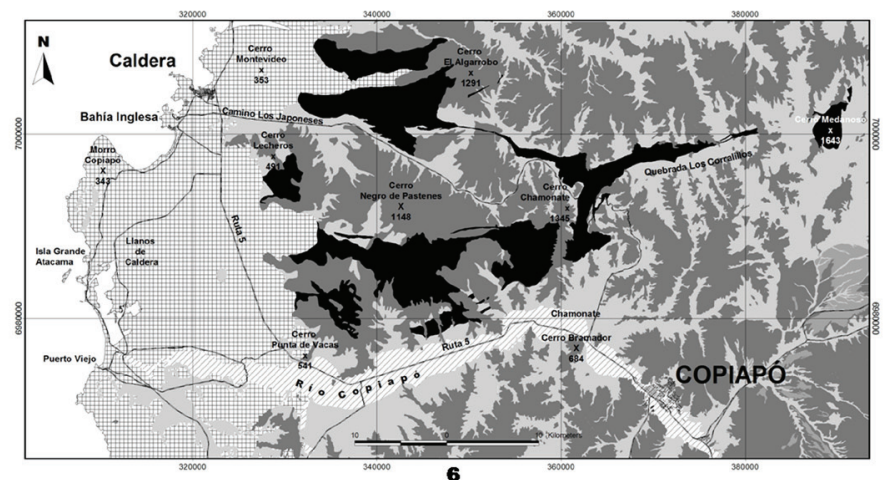

Geomorfología $12 \%$

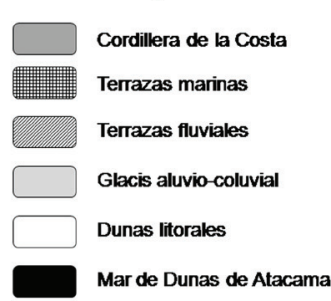

Fuente: Castro et al. (2012) 

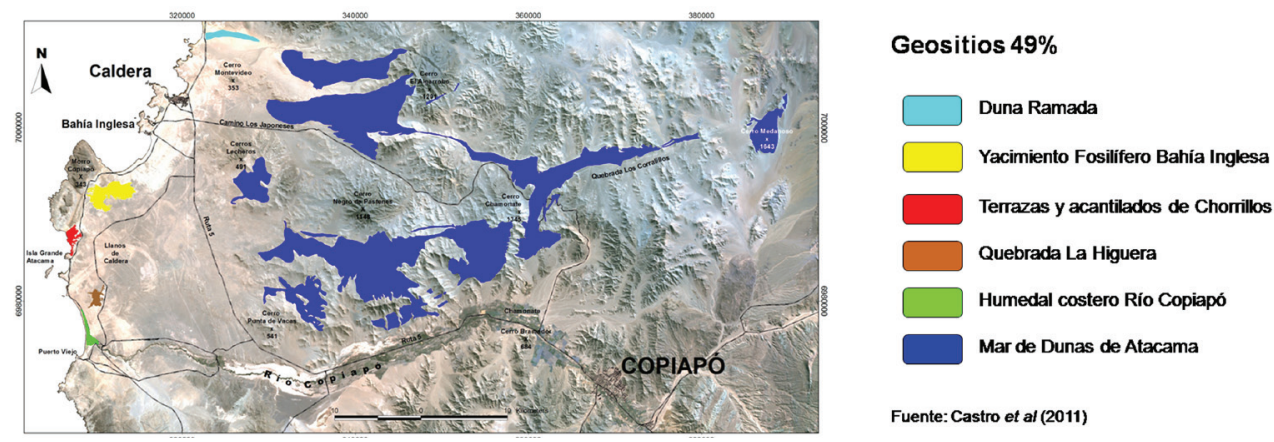

Fuente: Castro et al (2011)

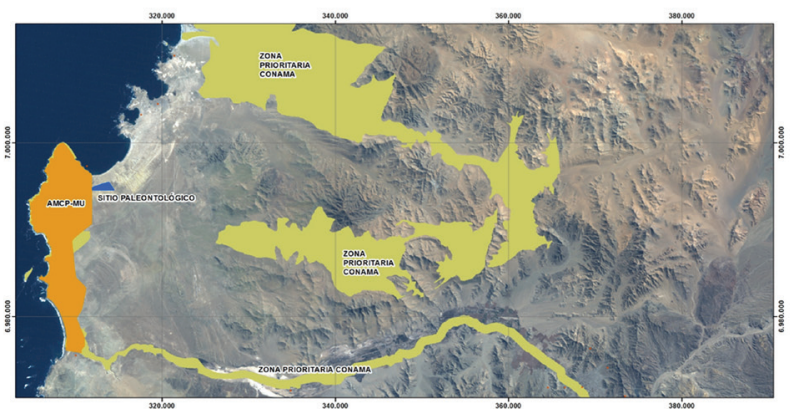

Áreas de protección $24 \%$

Fig. 3: Coberturas de cada criterio de valoración.

Fig. 3: Layers for each valorization criteria.

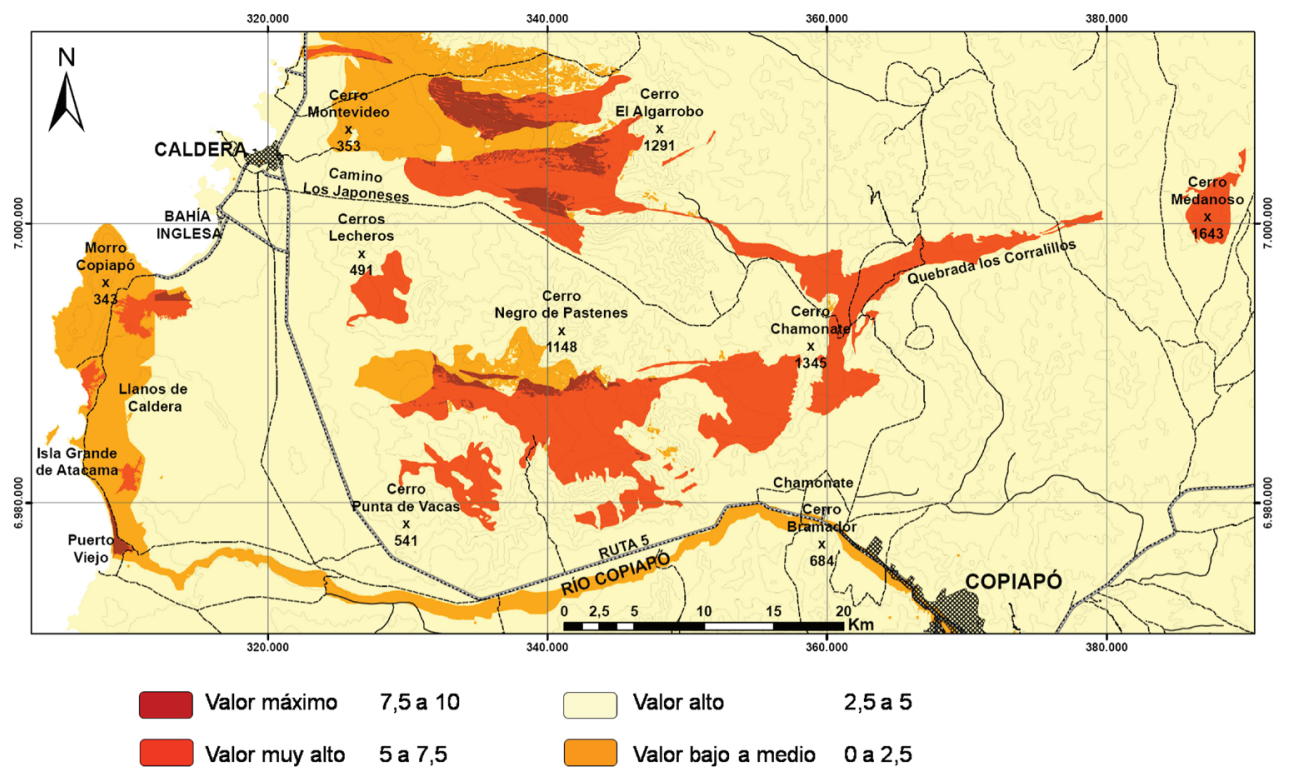

Fig. 4. Zonificación del área costera de Atacama basada en análisis multicriterio. Fuente: Los autores.

Fig. 4. Atacama's coastal area zoning based in multicriteria analisys. Source: The authors. 
En la Tabla 4 y la figura 5 se señala por ejemplo que, las unidades Mar de Dunas Bajo Norte (4) y Mar de Dunas Bajo Sur (5), corresponden a las unidades territoriales de mayor importancia geopatrimonial al estar constituidas por polígonos valorados en tres categorías: alto, muy alto y máximo, que combinan cuatro criterios de valoración: geositio, áreas de protección, vegetación y geomorfología. Esto significa que la unidad contiene diferentes elementos de importancia patrimonial, parte del geositio Mar de Dunas de Atacama (CASTRO et al. 2011), por coincidir con una zona prioritaria (SQUEO et al. 2008) y también, por la ocurrencia del desierto florido en los sustratos de la terraza marina de dicha unidad (CASTRO et al. 2013, en prensa; CASTRO et al. 2012). De igual modo, la unidad Yacimiento Fosilífero Bahía Inglesa (11) combina tres criterios de valoración en que, protección y calidad de geositio, le otorgan su mayor ponderación y cantidad de elementos de importancia. En efecto, esta unidad forma parte del Área
Marina Costera de Múltiples Usos (AMCP$\mathrm{MU}$ ), por sus cualidades ha sido propuesta como geositio por los autores y además, es un Parque Paleontológico de acuerdo al Decreto Exento $N^{\circ} 271$ Mayo de 2007 del Ministerio de Bienes Nacionales (CASTRO et al. 2011).

La mayoría de las unidades reconocidas, según lo señalado en la Tabla 4 y en la figura 5 , resultan de polígonos únicos con categorías de valor muy alto o alto. Es así que la unidad territorial Cerro Medanoso (1), fue valorada en el rango muy alto, donde se combinan dos criterios de valoración que son geositio (49\%) y geomorfología (12\%). Los autores determinaron el sector de Cerro Medanoso como parte del geositio Mar de Dunas de Atacama (CASTRO et al. 2011) debido a la singularidad de formas de las dunas desérticas activas que sepultan el relieve subyacente y también, por los rasgos escénicos y paisajísticos del conjunto geomorfológico.

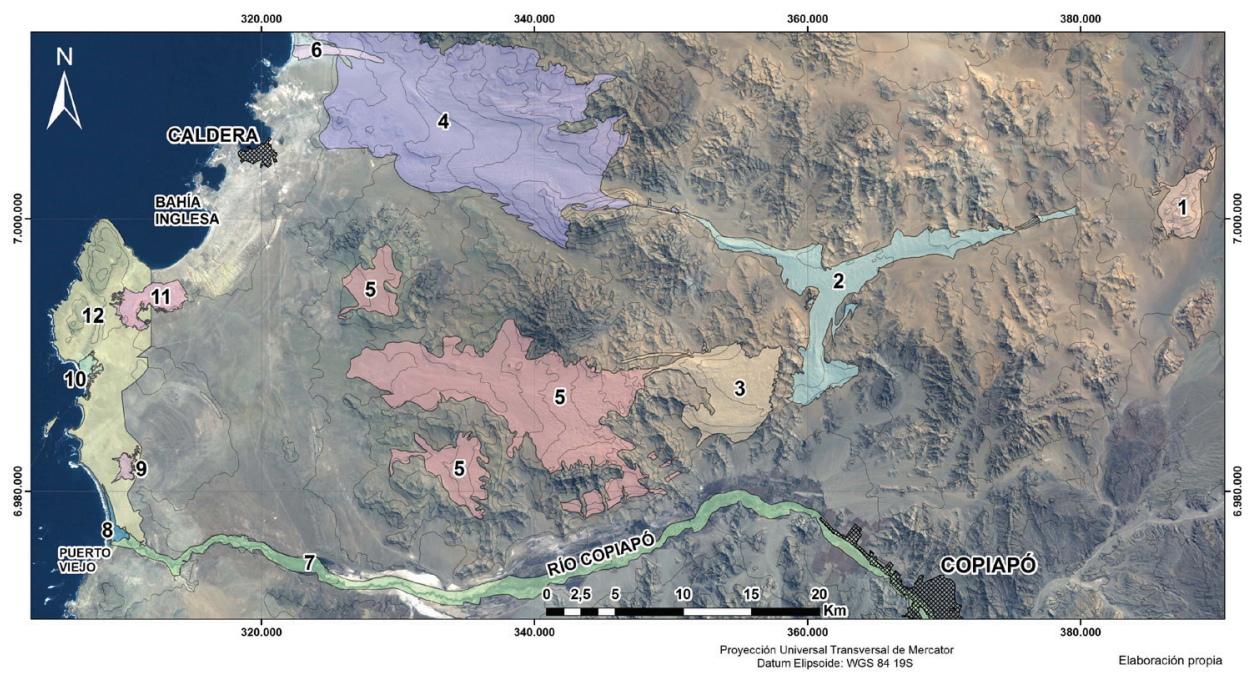

1. Cerro Medanoso, 2. Mar de Dunas Medio, 3. Mar de Dunas Alto, 4. Mar de Dunas Bajo Norte,

5. Mar de Dunas Bajo Sur, 6. Duna Ramada, 7. Lecho inferior rio Río Copiapó, 8. Humedal Costero desembocadura Río Copiapó, 9. Quebrada La Higuera, 10. Terrazas y acantilados marinos de Chorrillos, 11. Yacimiento fosilífero Bahía Inglesa, 12. Área Marina Costera Protegida de Múltiples Usos (AMCP-MU) Isla Grande de Atacama. Fuente: Elaboración propia.

Fig. 5. Unidades territoriales de valor geopatrimonial y natural en la zona costera del Sur de Atacama.

Fig. 5. Territorial units having natural and geoheritage interest in the coastal zone of the Southern Atacama Desert. 
Tabla 4: Zona costera del sur de Atacama: Unidades territoriales de Valor GEOPATRIMONIAL Y NATURAL.

Table 4: Coastal zone in the Southern Atacama Desert: Territorial units HAVING NATURAL AND GEOHERITAGE INTEREST.

\begin{tabular}{|c|c|c|c|}
\hline $\begin{array}{l}\text { Unidad } \\
\text { territorial }\end{array}$ & $\begin{array}{l}\text { Rango } \\
\text { de Valor }\end{array}$ & Elementos de valoración & $\begin{array}{c}\text { Usos y actividades } \\
\text { actuales }\end{array}$ \\
\hline $\begin{array}{c}\text { 1.Cerro } \\
\text { Medanoso }\end{array}$ & $\begin{array}{c}5 \text { a } 7,5 \\
\text { muy alto }\end{array}$ & $\begin{array}{c}\text { Geositio } \\
\text {-Mar de Dunas de Atacama } \\
\text { Geomorfología } \\
\text {-Diversidad de dunas desérticas }\end{array}$ & $\begin{array}{l}\text {-Rally Dakar } \\
\text {-Raid de Atacama } \\
\text {-Jeepeo } \\
\text {-Deslizamiento en } \\
\text { arena (sandboard) }\end{array}$ \\
\hline $\begin{array}{l}\text { 2.Mar de Dunas } \\
\text { medio }\end{array}$ & $\begin{array}{c}5 \text { a } 7,5 \\
\text { muy alto }\end{array}$ & $\begin{array}{c}\text { Geositio } \\
\text {-Mar de Dunas de Atacama } \\
\text { Área de protección } \\
\text {-Zonas prioritaria CONAMA } \\
\text { Geomorfología } \\
\text {-Diversidad de dunas desérticas }\end{array}$ & $\begin{array}{c}\text {-Rally Dakar } \\
\text {-Raid de Atacama } \\
\text {-Jeepeo }\end{array}$ \\
\hline $\begin{array}{l}\text { 3.Mar de Dunas } \\
\text { alto }\end{array}$ & $\begin{array}{l}5 \text { a } 7,5 \\
\text { muy alto }\end{array}$ & $\begin{array}{c}\text { Geositio } \\
\text {-Mar de Dunas de Atacama } \\
\text { Área de protección } \\
\text {-Zona prioritaria CONAMA } \\
\text { Geomorfología } \\
\text {-Diversidad de dunas desérticas }\end{array}$ & $\begin{array}{c}\text {-Rally Dakar } \\
\text {-Raid de Atacama } \\
\text {-Jeepeo } \\
\text {-Minería (en su } \\
\text { entorno) } \\
\text {-Caminos, huellas } \\
\text {-Líneas de } \\
\text { transmisión eléctrica }\end{array}$ \\
\hline $\begin{array}{l}\text { 4.Mar de Dunas } \\
\text { Bajo Norte }\end{array}$ & $\begin{array}{l}2,5 \text { a } 5 \\
\text { alto } \\
5 \text { a } 7,5 \\
\text { muy alto } \\
7,5 \text { a } 10 \\
\text { máximo }\end{array}$ & $\begin{array}{c}\text { Geositio } \\
\text {-Mar de Dunas de Atacama } \\
\text { Área de protección } \\
\text {-Zona prioritaria CONAMA } \\
\text { Vegetación } \\
\text {-Desierto florido } \\
\text {-Tillandsias } \\
\text { Geomorfología } \\
\text {-Formas de dunas desérticas } \\
\text { Terrazas marinas }\end{array}$ & $\begin{array}{c}\text {-Rally Dakar } \\
\text {-Raid de Atacama } \\
\text {-Jeepeo } \\
\text {-Minería } \\
\text {-Vertedero de basuras } \\
\text {-Ejercicios militares } \\
\text {-Mineraducto } \\
\text {-Líneas de } \\
\text { transmisión eléctrica } \\
\text {-Caminos, huellas }\end{array}$ \\
\hline $\begin{array}{l}\text { 5.Mar de Dunas } \\
\text { Bajo Sur }\end{array}$ & $\begin{array}{l}2,5 \text { a } 5 \\
\text { alto } \\
5 \text { a } 7,5 \\
\text { muy alto } \\
7,5 \text { a } 10 \\
\text { máximo }\end{array}$ & $\begin{array}{c}\text { Geositio } \\
\text {-Mar de Dunas de Atacama } \\
\text { Área de protección } \\
\text {-Zona prioritaria CONAMA } \\
\text { Vegetación } \\
\text {-Desierto florido } \\
\text { Geomorfología } \\
\text {-Formas de dunas activas } \\
\text {-Terrazas marinas } \\
\end{array}$ & $\begin{array}{c}\text {-Rally Dakar } \\
\text {-Raid de Atacama } \\
\text {-Jeepeo } \\
\text {-Minería } \\
\text {-Ejercicios militares } \\
\text {-Mineraductos } \\
\text {-Líneas de } \\
\text { transmisión eléctrica } \\
\text {-Caminos, huellas } \\
\end{array}$ \\
\hline 6.Duna Ramada & $\begin{array}{l}5 \text { a } 7,5 \\
\text { muy alto }\end{array}$ & $\begin{array}{c}\text { Geositio (propuesta autores) } \\
\text {-Duna Ramada } \\
\text { Área de protección } \\
\text {-Zona prioritaria CONAMA } \\
\text { Geomorfología } \\
\text {-Duna costera lineal compuesta } \\
\text {-Terraza marina } \\
\text {-Playa arenosa }\end{array}$ & $\begin{array}{c}\text {-Jeepeo } \\
\text {-Mineraductos } \\
\text {-Líneas de } \\
\text { transmisión eléctrica } \\
\text {-Caminos, huellas }\end{array}$ \\
\hline
\end{tabular}




\begin{tabular}{|c|c|c|c|}
\hline $\begin{array}{l}\text { Unidad } \\
\text { territorial }\end{array}$ & $\begin{array}{c}\text { Rango } \\
\text { de Valor }\end{array}$ & Elementos de valoración & $\begin{array}{c}\text { Usos y actividades } \\
\text { actuales }\end{array}$ \\
\hline $\begin{array}{l}\text { 7.Lecho inferior } \\
\text { rio Río Copiapó }\end{array}$ & $\begin{array}{l}2,5 \text { a } 5 \\
\quad \text { alto }\end{array}$ & $\begin{array}{c}\text { Área de protección } \\
\text {-Zona prioritaria CONAMA } \\
\text { Vegetación } \\
\text {-Otra vegetación nativa } \\
\text {-Plantaciones agrícolas }\end{array}$ & $\begin{array}{c}\text {-Agricultura } \\
\text {-Otras actividades } \\
\text { productivas } \\
\text { (agroindustria) } \\
\text {-Zonas pobladas } \\
\text { - Carreteras, caminos, } \\
\text { huellas } \\
\text {-Líneas de } \\
\text { transmisión eléctricas } \\
\text {-Ductos }\end{array}$ \\
\hline $\begin{array}{l}\text { 8. Humedal } \\
\text { Costero } \\
\text { Desembocadura } \\
\text { Río Copiapó }\end{array}$ & $\begin{array}{l}7,5 \text { a } 10 \\
\text { máximo }\end{array}$ & $\begin{array}{c}\text { Geositio (propuesta autores) } \\
\text {-Humedal costero Río Copiapó } \\
\text { Área de protección } \\
\text {-Área Marina Costera de Múltiples Usos } \\
\text { Isla Grande Atacama (AMCP-MU) } \\
\text { Vegetación } \\
\text {-Vegetación de humedal } \\
\text { Geomorfología } \\
\text {-Duna litorales } \\
\text {-Laguna litoral } \\
\text {-Río Copiapó }\end{array}$ & $\begin{array}{c}\text {-Campismo } \\
\text {-Pesca } \\
\text {-Jeepeo } \\
\text {-Transito vehículos } \\
\text {-Caminos, huellas }\end{array}$ \\
\hline $\begin{array}{c}\text { 9.Quebrada La } \\
\text { Higuera }\end{array}$ & $\begin{array}{c}5 \text { a } 7,5 \\
\text { muy alto }\end{array}$ & $\begin{array}{c}\text { Geositio (propuesta autores) } \\
\text {-Quebrada La Higuera } \\
\text { Área de protección } \\
\text {-Área Marina Costera de Múltiples Usos } \\
\text { Isla Grande Atacama (AMCP-MU) } \\
\text { Geomorfología } \\
\text {-Terrazas marinas erosionadas } \\
\text {-Formas de erosión fluvial y eólico }\end{array}$ & -Jeepeo \\
\hline $\begin{array}{l}\text { 10. Terrazas } \\
\text { y acantilados } \\
\text { marinos de } \\
\text { Chorrillos }\end{array}$ & $\begin{array}{c}5 \text { a } 7,5 \\
\text { muy alto }\end{array}$ & $\begin{array}{c}\text { Geositio (propuesta autores) } \\
\text {-Terrazas y acantilados marinos de } \\
\text { Chorrillos } \\
\text { Área de protección } \\
\text { Área Marina Costera de Múltiples Usos } \\
\text { Isla Grande Atacama (AMCP-MU) } \\
\text { Geomorfología } \\
\text {-Terrazas marinas erosionadas } \\
\text { (restos fósiles) } \\
\text {-Formas de erosión fluvial y eólico } \\
\text {-Acantilados marinos }\end{array}$ & $\begin{array}{c}\text {-Jeepeo } \\
\text {-Turismo de playa }\end{array}$ \\
\hline $\begin{array}{c}\text { 11.Yacimiento } \\
\text { fosilífero Bahía } \\
\text { Inglesa }\end{array}$ & $\begin{array}{c}5 \text { a } 7,5 \\
\text { muy alto } \\
7,5 \text { a } 10 \\
\text { máximo }\end{array}$ & $\begin{array}{c}\text { Geositio (propuesta autores) } \\
\text {-Yacimiento Fosilífero Bahía Inglesa } \\
\text { Área de protección } \\
\text {-Área Marina Costera de Múltiples Usos } \\
\text { Isla Grande Atacama (AMCP-MU) } \\
\text {-Parque Paleontológico } \\
\text { Geomorfología } \\
\text {-Terrazas marinas erosionadas } \\
\text { (restos fósiles) } \\
\text {-Formas de erosión fluvial y eólico }\end{array}$ & $\begin{array}{c}\text {-Jeepeo } \\
\text {-Minería } \\
\text {-Extracción de fósiles }\end{array}$ \\
\hline $\begin{array}{c}\text { 12. Área } \\
\text { Marina Costera } \\
\text { Protegida de } \\
\text { Múltiples Usos } \\
\text { (AMCP-MU) } \\
\text { Isla Grande de } \\
\text { Atacama. }\end{array}$ & $\begin{array}{l}2,5 \text { a } 5 \\
\text { alto }\end{array}$ & $\begin{array}{c}\text { Área de protección } \\
\text { Área Marina Costera de Múltiples Usos } \\
\text { Isla Grande Atacama (AMCP-MU) } \\
\text {-Geomorfología } \\
\text {-Terrazas marinas erosionadas (restos } \\
\text { fósiles) } \\
\text {-Formas de erosión fluvial y eólico } \\
\text {-Acantilados marinos } \\
\text {-Playas }\end{array}$ & $\begin{array}{c}\text {-Campismo } \\
\text {-Pesca } \\
\text {-Jeepeo } \\
\text {-Transito vehículos } \\
\text {-Caminos, huellas } \\
\text {-Turismo de playa }\end{array}$ \\
\hline
\end{tabular}




\begin{tabular}{|c|c|c|c|}
\hline $\begin{array}{c}\text { Unidad } \\
\text { territorial }\end{array}$ & $\begin{array}{l}\text { Rango } \\
\text { de Valor }\end{array}$ & Elementos de valoración & $\begin{array}{c}\text { Usos y actividades } \\
\text { actuales }\end{array}$ \\
\hline $\begin{array}{l}\text { 13. Resto área } \\
\text { de estudio }\end{array}$ & 0 a 2,5 & $\begin{array}{c}\text { Geomorfología } \\
\text {-Terrazas marinas } \\
\text {-Cerros } \\
\text {-Valles } \\
\text {-Planos inclinados y glacis }\end{array}$ & $\begin{array}{c}\text {-Zonas pobladas } \\
\text {-Agricultura } \\
\text {-Otras actividades } \\
\text { productivas } \\
\text { (agroindustria) } \\
\text { - Carreteras, caminos, } \\
\text { huellas } \\
\text {-Líneas de } \\
\text { transmisión eléctricas } \\
\text {-Ductos } \\
\text {-Campismo } \\
\text {-Pesca } \\
\text {-Jeepeo } \\
\text {-Transito vehículos } \\
\text {-Caminos, huellas } \\
\text {-Turismo de playa } \\
\text {-Otras }\end{array}$ \\
\hline
\end{tabular}

Fuente: Autores

Respectivamente, las unidades territoriales en la Tabla 4, tienen distintos rangos de valoración cuya diferenciación se explica por las diversas combinaciones de los elementos de importancia geopatrimonial que se dan en la unidad. De acuerdo con lo anterior, las áreas de valores máximos, o significativas, deben ser protegidas y caracterizadas con estudios específicos de sitio puesto que, el rango de valor alto es el más restrictivo para los usos y actividades que allí puedan realizarse. Estos lugares corresponden a sectores del Mar de Dunas en donde se hallan todos los elementos de valoración; posee la categoría de área prioritaria; se localiza allí un geositio; es un área con vegetación de niebla y ocurrencia del desierto florido. Este último, es uno de los más importantes atractivos turísticos de la Región y se puede potenciar su valor percibido, integrando los elementos del geopatrimonio.

Las áreas calificadas con valor muy alto corresponden a las unidades espaciales donde se localiza un geositio, coincidiendo además con área de protección; dichos sectores deben tener usos restrictivos con una adecuada regulación en relación con la actividad que se desee implementar, tales como geoturismo; observación de la naturaleza; investigación y educación.

Los lugares con rango de valor alto, se sitúan en los márgenes del Mar de Dunas donde ocurre con mayor vigor el desierto florido; también se agrupan en esta categoría, las áreas vegetadas del lecho del río Copiapó.

Según el resultado de la valoración de las unidades territoriales y los tipos de usos $\mathrm{y}$ actividades humanas que actualmente se efectúan en el área, se presenta en la Tabla 5 una propuesta preliminar con recomendaciones generales para cada unidad según su relevancia geopatrimonial. La asignación específica de los usos compatibles en cada unidad territorial, debe efectuarse según estudios de sitio, elaborando guías científicas de manejo y cartografía detallada de la unidad respectiva (CASTRO et al. 2010). En tal documento de utilidad para la gestión, debieran considerarse los resultados de la valoración del geopatrimonio que aquí se presenta, junto a otros aspectos como normativas e instrumentos de regulación territorial existentes; propiedad de la tierra; 
pedimentos de explotación minera, entre otros, según sea la unidad territorial de que se trate. La mayor parte del territorio en estudio pertenece a Bienes Nacionales que es el organismo que tiene la facultad de su administracion; sin embargo, por tratarse de territorios de riqueza minera de hierro y cobre, hay una gran cantidad de solicitudes de pedimentos mineros para la explotación del subsuelo.

\section{Tabla 5: Recomendaciones Generales para las Unidades Territoriales de valor GEOPATRIMONIAL Y NATURAL.}

TABle 5: RECOMMENDATIONS FOR TERRITORIAL UNITS WITH GEOHERITAGE AND NATURAL VALUE.

\begin{tabular}{|c|c|c|c|c|c|c|c|c|c|}
\hline \multirow{2}{*}{ Categoría de valor } & \multirow{2}{*}{ Unidad territorial } & \multicolumn{8}{|c|}{ Recomendaciones } \\
\hline & & 1 & 2 & 3 & 4 & 5 & 6 & 7 & 8 \\
\hline \multirow{3}{*}{$\begin{array}{l}\text { Valor máximo } \\
\qquad 7,5 \text { a } 10\end{array}$} & 4.Mar de Dunas Bajo Norte & $x$ & & & & $x$ & $x$ & $x$ & $x$ \\
\hline & 5.Mar de Dunas Bajo Sur & $x$ & & & & $x$ & $x$ & $x$ & $x$ \\
\hline & $\begin{array}{l}\text { 11.Yacimiento Fosilífero Bahía } \\
\text { Inglesa }\end{array}$ & $x$ & & & & $x$ & $x$ & $x$ & $x$ \\
\hline \multirow{7}{*}{$\begin{array}{l}\text { Valor muy alto } \\
\qquad 5 \text { a } 7,5\end{array}$} & 1.Cerro Medanoso & & $x$ & $x$ & $x$ & $x$ & $x$ & $x$ & \\
\hline & 2.Mar de Dunas medio & & $x$ & $x$ & $x$ & $x$ & $x$ & $x$ & \\
\hline & 3.Mar de Dunas alto & & $x$ & $x$ & $x$ & $x$ & $x$ & $x$ & \\
\hline & 6.Duna Ramada & & $x$ & $x$ & $x$ & $x$ & $x$ & $x$ & $x$ \\
\hline & $\begin{array}{l}\text { 8. Humedal Costero desembocadura } \\
\text { Río Copiapó }\end{array}$ & $x$ & & & & $x$ & $x$ & $x$ & $x$ \\
\hline & 9.Quebrada La Higuera & $\mathrm{x}$ & & & & $x$ & $x$ & $x$ & $x$ \\
\hline & $\begin{array}{l}\text { 10. Terrazas y acantilados marinos } \\
\text { de Chorrillos }\end{array}$ & $x$ & & & & $\mathrm{x}$ & $x$ & $x$ & $x$ \\
\hline \multirow{2}{*}{$\begin{array}{l}\text { Valor alto } \\
2,5 \text { a } 5\end{array}$} & 12. AMCP-MU Isla Grande Atacama & & $x$ & $x$ & $x$ & $x$ & $x$ & $x$ & \\
\hline & 7.Lecho inferior rio Río Copiapó & & $x$ & $x$ & & & & $x$ & \\
\hline $\begin{array}{l}\text { Valor bajo a medio } \\
\qquad 0 \text { a } 2,5\end{array}$ & 13. Resto área de estudio & & & & & & $x$ & $x$ & \\
\hline & & 1 & 2 & 3 & 4 & 5 & 6 & 7 & 8 \\
\hline
\end{tabular}

Deacuerdoalo anterior, las recomendaciones generales para las unidades territoriales valoradas se señalan a continuación:

1. No autorizar actividades productivas e instalación de infraestructura que afecte la naturalidad de la unidad.

2. Promover las actividades tendientes a regular las actividades productivas $\mathrm{y}$ otras que se efectúan en el área como son la minería extractiva, los ejercicios militares, los vertederos de basura y botadores de escombros y rellenos.

3. Regulación de la infraestructura instalada como son los caminos de acceso a faenas mineras, el tendido eléctrico, los ductos mineros, las postaciones, en lo relativo a su trazado y envergadura. 
4. Establecimiento y control de las normas regulatorias para las actividades motorizadas deportivas en cuanto al trazado de trayectos, la periodicidad, los controles del público asistente.

5. Fomentar las actividades recreacionales, geoturismo y turismo de intereses especiales, realización de acciones culturales y educativas.

6. Realizar estudios técnicos específicos de acuerdo al tipo de uso o actividad (impacto en ecosistemas, capacidad de carga, compatibilidad de usos, entre otros).

7. Fiscalizar el cumplimiento de las normas ambientales generales existentes.

8. Propender a elevar la condición actual de protección existente, por ejemplo de zona prioritaria a santuario.

Finalmente, se continuará con la divulgación científica de los resultados de este y otros trabajos, en las instancias científicas, administrativas, políticas y eduacacionales, para propender en el futuro a solicitar la categoría UNESCO de geoparque para dicho territorio.

Por otra parte, el objetivo de conservación de la integridad de las unidades territoriales de relevancia geopatrimonial, como lo expresan CARCAVILLA et al. (2007), es la mantención de su valor ambiental actual, junto con sus características naturales y los procesos dinámicos de su modelado. Dichas unidades territoriales del área de estudio, en la actualidad, son susceptibles a soportar transformaciones o degradación por causas antrópicas y en varios sectores se encuentran potencialmente amenazadas por la proliferación de actividades mineras extractivas de hierro y cobre y por las peticiones actuales de explotación de las arenas del Mar de Dunas. Respecto a lo último, una posibilidad de revaloración de sectores en los cuales la actividad extractiva de minerales ya no se efectúa, como ocurre con algunas minas abandonadas en el área, es la descrita por ARMESTO (2002) en relación a la creación de parques geomineros que son áreas en que se protege el patrimonio geológico, minero y geomorfológico ubicadas en ellas, acondicionándolas para que puedan ser visitadas por el público con un objetivo lúdico, didáctico o de investigación; así se conjuga el patrimonio natural y el patrimonio antropogénico formado por las labores, faenas e instalaciones mineras.

Una interesante iniciativa para llevar a cabo en el área de estudio en Atacama, es la promoción del geoturismo y turismo de intereses especiales, con el particular cuidado de promocionarlo entre los habitantes de las localidades de la región, como lo recomiendan CARCAVILLA et al. (2007) con el fin de divulgar su valor y el significado de los recursos que poseen, ya que dicho geopatrimonio constituye un elemento significativo para la promoción de la Región, como son las competencias deportivas del Rally y Raid de Atacama en el Mar de Dunas y también el desierto florido. En efecto, ellos son recursos turísticos distintivos y representativos de la Región de Atacama que, con planes de manejo adecuados pueden sostener las actividades mencionadas.

Finalmente, para promover la conservación se requiere la divulgación del geopatrimonio, lo cual debe ser un proceso pensado dentro de un plan global de gestión, adaptado a las características del lugary a su fragilidad, según las palabras de CARCAVILLA et al. (2007), quienes expresan que dicha divulgación del geopatrimonio es un conjunto de acciones encaminadas a transmitir al público su valor con el fin de promover su comprensión y a estimular actitudes orientadas a la conservación. La mayoría de las unidades territoriales determinadas (Fig. 5), no han sido degradadas, pero son vulnerables y no 
se cuenta para dichos lugares con sistemas de gestión específicos que garanticen su conservación, como lo plantean DIXON et al. (1997), en relación a las herramientas necesarias para la valoración y ordenación del territorio de valor geopatrimonial. En este sentido, en Chile, MARQUARDT et al. (2007) señalan que para vincular la política nacional de protección y difusión del geopatrimonio y las políticas orientadas al desarrollo local y regional, se debiera considerar promover el estudio científico de los Parques Nacionales ya existentes en el territorio nacional para evaluar su potencialidad como geoparques, cosa que ya está ocurriendo con el proyecto conducente a la creación del primer geoparque de Chile en el Parque Nacional Conguillío, en el Territorio Andino de la Región de la Araucanía, iniciativa que pretende marcar un precedente en la valoración del patrimonio geológico nacional (SCHILLING et al. 2009).

En este contexto, se propone que con el conocimiento actual sobre el geopatrimonio de la zona costera de Atacama, se discuta la factibilidad de la postulación a la nominación y creación de un geoparque que también comprenda el territorio del Área Marino y Costero Protegida de Mútiples Usos Isla Grande de Atacama, el Parque Paleontológico y las áreas prioritarias para la conservación, según se observa en la figura 4.

\section{DISCUSIÓN}

Este artículo se plantea con un enfoque dirigido a la puesta en valor del medio natural abiótico, esto es, a difundir y explicar la relevancia de la protección de la geodiversidad del territorio (MURRAY 2004), la cual corresponde a la variedad de elementos geológicos, incluidos, rocas, minerales, fósiles, suelos, formas del relieve, formaciones y unidades geológicas y paisajes que son el producto y registro de la evolución de la Tierra, INSTITUTO GEOLÓGICO Y MINERO DE ESPAÑA
(2009). También, con el interés de destacar la importancia de la geodiversidad como recurso potencial para el desarrollo local y regional, según los postulados de UNESCO (1999). En efecto, respecto a lo último, Chile se hace parte de las iniciativas de UNESCO al iniciar recientemente los estudios de normalización para llevar a cabo un catastro de geositios en el país, y la iniciativa de la creación del primer geoparque en la zona cordillerana de la Región de la Araucanía (SCHILLING 2009).

Así mismo, es preciso señalar que la realización de estudios de análisis integrado requiere poseer una fuente de datos muy diversa, que sean confiables y que puedan ser espacializados en coberturas temáticas. En este estudio, se dispuso de los trabajos previos, citados en el texto, de ARAYAVERGARA (2001), ARÉVALO, (2005), GODOY et al. (2003), PASKOFF et al. (2003), SQUEO et al. (2007), SQUEO et al. (2008), SUAREZ et al. (2003), sobre aspectos geomorfológicos, geológicos, paleontológicos y de vegetación del área de estudio. Por su parte los autores de este trabajo, aportaron a la base de datos integrados con los resultados de investigaciones previas sobre la geomorfología y morfodinámica de la zona costera de Atacama (CASTRO et al. 2012); como también, la propuesta de geositios de CASTRO (2007), CASTRO et al. (2010) con sus respectivas guías de manejo, y finalmente el estudio de la distribución espacial de la vegetación (CASTRO et al. 2013, en prensa).

En relación a los procedimientos de valoración de las unidades territoriales, es imprescindible aminorar o evitar los sesgos de subjetividad en las ponderaciones. En este sentido, las propuestas de CENDRERO (1996), PEREIRA et al. (2007), CARCAVILLA et al. (2007) para la valoración del geopatrimonio y particularmente de geositios, fueron tomados en cuenta en esta investigación con las adecuaciones necesarias para la valoración de 
unidades territoriales, las cuales representan un conjunto de elementos abióticos y también vegetación a valorar, como se explica en la metodología. Los criterios de valoración de geositios enunciados por CENDRERO (1996) y también utilizados en la metodología de valoración del INSTITUTO GEOLÓGICO Y MINERO DE ESPAÑA (2009), representan tres grandes categorías de cualidades a considerar en un inventario del geopatrimonio, y son el valor intrínseco, la potencialidad de uso y la necesidad de protección del elemento del geopatrimonio que se evalúa. Por su parte PEREIRA et al. (2007), hacen énfasis en la necesidad de efectuar primero un inventario y posteriormente una cuantificación, que consiste en la puntuación de criterios relativos al valor geológico/geomorfológico y valor de gestión.

En este artículo, la asignación de valor a las unidades territoriales pone énfasis en los criterios geomorfológicos y la existencia de un geositio en la unidad espacial considerada, puesto que ellos son los elementos relacionados directamente con la protección de la geodiversidad. En este sentido, las categorías de valoración propuestas se expresan en términos cualitativos como máximo, muy alto, alto, medio, bajo; categorías susceptibles de ser discutidas. Al respecto, dados los elementos naturales bióticos y abióticos existentes en el área de estudio, los autores estiman que las unidades territoriales definidas poseen en su mayoría un alto valor intrínseco, según la acepción de CENDRERO (1996) que ha sido reafirmada por los diversos investigadores del geopatrimonio posteriormente; por ello, resulta para el conjunto de las unidades territoriales estudiadas, una puntuación en categorías de valoración elevada.

Por otra parte, en la Región de Atacama hay escases de instrumentos de planificación integrada, y este estudio aporta tanto información de línea base, como también, una metodología de valoración integrada del territorio que intenta ser objetiva considerando que los elementos calificados, tales como el geopatrimonio, las áreas protegidas y otros, tienen un valor cualitativo difícil de medir y expresar neutralmente. Así, se pudo relacionar a través de la metodología utilizada, elementos bióticos y abióticos, a partir de la normalización en la aplicación de una misma escala de valores utilizada por cada uno de los especialistas del grupo de trabajo y de los expertos invitados, constituyendo un enfoque multidisciplinario.

Respecto a las dificultades de la valoración del geopatrimonio, CARACAVILLA et al. (2007), hacen un detallado análisis y comentario de los diferentes sistemas aplicados hasta ahora; de acuerdo a ello, el presente trabajo empleó un sistema cualitativo-cuantitativo, en el cual se combinan las ventajas de simpleza y rapidez del registro de las características cualitativas de un lugar, con la determinación cuantitativa de valores que permiten ordenar por intervalos y establecer escalas de importancia de las unidades territoriales determinadas.

\section{CONCLUSIONES}

Se efectuó la zonificación de la zona costera del sur de Atacama, en unidades territoriales valoradas según su importancia geopatrimonial, como base científica para orientar su protección y uso armónico, compatible con las características naturales de dichas áreas. Lo anterior se expresa en una cartografía de unidades territoriales con valor patrimonial y natural, delimitando las zonas que debieran quedar afectas a regulaciones especiales por parte de los organismos e instituciones regionales competentes.

Los resultados obtenidos contribuirán a las iniciativas que recientemente se llevan a cabo en Chile, para divulgar la relevancia del geopatrimonio como recurso potencial, y para la búsqueda y aplicación de metodologías para el inventario y diagnóstico de los lugares de interés nacional. 
Aplicando una metodología de análisis espacial muticriterio, se identificaron 12 unidades espaciales de importante valor geopatrimonial y natural en la zona costera en estudio. Se efectuó la caracterización y análisis individual de cada unidad territorial según los criterios de áreas de protección, existencia de geositios, relevancia geomorfológica, vegetación, señalados en la metodología los cuales apuntan a valorar los elementos abióticos que las determinan; contrastando sus particularidades propias con los usos $\mathrm{y}$ actividades humanas que actualmente se efectúan en ellas.

De acuerdo a lo anterior, se elaboró una propuesta de recomendaciones generales para orientar la asignación de usos compatibles con el valor geopatrimonial y natural de las unidades territoriales. Se entrega una propuesta de recomendaciones específicas para cada grupo de unidades territoriales, según su rango de valor; dichas indicaciones son de tipo restrictivas, regulatorias, de fomento, fiscalización, de protección.

Se espera llevar a cabo una amplia difusión de los resultados en el medio local y regional, para propender a crear las bases para el establecimiento de un proyecto de creación de un geoparque que incluya el territorio estudiado, el espacio del Área Marina y Costera protegida Isla Grande de Atacama, junto con los geositios propuestos y, las áreas prioritarias para la conservación de la biodiversidad existentes.

\section{AGRADECIMIENTOS}

Los autores agradecen a Fondecyt el financiamiento del proyecto de investigación $\mathrm{N}^{\circ} 1100400$. También un especial reconocimiento a Juan Manuel Barragán, Francisco Chirino, Jorge Espinoza, Carlos Marquardt, Maria Luisa Perez-Cayeiro, Patricio Rios, Mario Suárez, por su colaboración en las consultas conducentes a la valoración del geopatrimonio en el área de estudio.

\section{REFERENCIAS}

ARAYA-VERGARA，J. 2001. Los Ergs del desierto marginal de Atacama, Chile. Investigaciones Geográficas Chile, 35: 27-66.

ARMESTO, J.L. 2002. Metodología para la transformación de labores mineras en parques temáticos. Proyecto fin de carrera. Escuelas Técnica Superior de Ingenieros de Minas. Universidad de Vigo. 131 pp.

ARÉVALO, C. 2005. Carta Copiapó, Región de Atacama. Servicio Nacional de Geología y Minería. Carta Geológica de Chile, Serie Geología Básica, No. 91.

BARREDO, J.I. 1996. Sistemas de Información Geográfica y Evaluación multicriterio. Editorial Ra-Ma. Madrid. 264 pp.

CARCAVILLA, L., J. LÓPEZ MARTÍNEZ \& J.J. DURÁN, 2007. Patrimonio geológico y geodiversidad: investigación, conservación, gestión y relación con los espacios naturales protegidos. Serie Cuadernos del Museo Geominero, 7. Instituto Geológico y Minero de España, Madrid. 360 pp.

CASTRO, C. 2007. Geositios de valor patrimonial en Isla Grande de Atacama. En: Áreas marinas y costeras protegidas de múltiples usos. Gobierno de Chile; Gef Marino; PNUD. Ocho Libros Editores; 110-115.

CASTRO, C., C. MARQUARDT \& A. ZÚÑIGA, 2010. Peligros naturales en geositios del litoral de Atacama. Rev. Geogr. Norte Grande, 45:21-39.

CASTRO, C., C. MARQUARDT \& A. ZÚÑIGA. 2011. Geositios de Caldera y Copiapó, Región de Atacama, Chile. Actas Conferencia Geográfica Regional UGI, Santiago de Chile, 5 pp. 
CASTRO, C., A. ZÚÑIGA \& C. PATTILLO, 2012. Geomorfología y geopatrimonio del Mar de Dunas de Atacama, Copiapó $\left(27^{\circ} \mathrm{S}\right)$, Chile. Rev. Geogr. Norte Grande, 53:123-136.

CASTRO, C., C. PATTILlo,A.ZÚÑ̃IGA \& A. MONTAÑA, 2013. Determinación del Área con Desierto Florido en el Mar de Dunas de Copiapó, Región de Atacama, Chile, Mediante Percepción Remota. (en prensa, Rev. Geogr. Norte Grande, 21pp).

CENDRERO, A. 1996. El patrimonio geológico: Bases para su valoración, protección, conservación y utilización. Ministerio de Obras Públicas, Transporte y Medio Ambiente (MOPT), Serie Monografías. España. pp. 17- 38.

DIXON, G., C. SHARPLES, I. HOUSHOLD, M. PEMBERTON, \& R. EBERHARD, 1997. Conservation Management Guidelines for Geodiversity. Tasmanian Regional Forest Agreement Environment and Heritage Technical Committee. 70 pp.

GODOY, E., C. MARQUARDT, \& N. BLANCO, 2003. Carta Caldera, Región de Atacama. Servicio Nacional de Geología y Minería. Carta Geológica de Chile, Serie Geología Básica, No. 76.

JUNTA DE ANDALUCIA. 2008. Estrategia Andaluza de Gestión Integrada de la Geodiversidad. Consejería del Medio Ambiente. Junta de Andalucía. 138 pp.

\section{INSTITUTO GEOLÓGICO Y MINERO} DE ESPAÑA. 2009. Documento Metodológico para la elaboración del inventario español de lugares de interés geológico. $61 \mathrm{pp}$.

MARQUARDT, C., M.E. NOEL, M.S. PADILLA \& F. HERVE, 2007. Herencia de la naturaleza. Patrimonio geológico y paleontológico, Rev. Geol. Chile, N³4, 5 pp.
MORTENSEN, H. 1927. Der Formenschatz der nordchilenischen Wuste. Abh. Ges. Wissensch., Gottingen, 12, 6 pp.

MURRAY, G. 2008. Geodiversity, valuing and conserving abiotic nature. Ed Wiley. $434 \mathrm{pp}$.

PASKOFF, R., L. CUITIÑO \& H. MANRIQUEZ, 2003. Origen de las arenas dunares de la región de Copiapó, Desierto de Atacama, Chile. Rev. Geol. Chile.30 (2): 355-361.

PEREIRA, P., D. INSUA PEREIRA \& M.I.C. ALVES, 2007. Avalacao do Patrimonio Geomorfológico: proposta de metodología. Publicacoes da Assiacao Portuguesa de Geomorfólogos, 5: 235-247.

SAATY, T. L. \& L. GONZÁLEZ, 2001. Models, Methods, Concepts \& Applications of the Analytic Hierarchy Process, ISBN 0-7923-7267-0, Kluwer Academic. 345 pp.

SQUEO, F.A. \& G. ARANCIO, 2007. Biodiversidad terrestre del AMCP-MU Isla Grande de Atacama. En: Áreas marinas y costeras protegidas de múltiples usos. Gobierno de Chile; Gef Marino; PNUD. Ocho Libros Editores; 83-89.

SQUEO, F.A. G. ARANCIO \& J.R. GUTIÉRREZ, 2008. Libro Rojo de la Flora Nativa y de los Sitios Prioritarios para su Conservación: Región de Atacama. Ediciones Universidad de La Serena, La Serena. 456 pp.

SCHILLING, M. 2009. Conguillío podría convertirse en el primer geoparque de Chile. Rev. Chile Forestal 344:26-29.

SUAREZ, M. C. MARQUARDT, M.E.NOEL, .B. SEPÚLVEDA \& T. ROJAS, 2003. Patrimonio natural y cultural de Caldera. III Región. Consejo de Monumentos Nacionales, 13 pp. UNESCO. 1999. Guidelines and Criteria for National Geoparks. 127 pp. 